\title{
MHD (MAGNETO-HYDRODYNAMICS) IN LIQUID METALS IN FUSION REACTORS: EFFECTS ON TRITIUM TRANSPORT AND INVENTORY
}

\author{
Ciro Alberghi ${ }^{1^{*}}$ \\ I"Polytechnic University of Torino, Energy Department "Galileo Ferraris", \\ Corso Duca degli Abruzzi 24, Torino, Italy;
}

*Corresponding author Ciro Alberghi, e-mail: ciro.alberghi@ polito.it;

Received November 2019; Accepted December 2019; Published January 2020;

DOI: https://doi.org/10.31407/ijees10.116

\begin{abstract}
The Water Cooled Lithium Lead (WCLL) is one of the breeding blanket concepts proposed for DEMO reactor. The velocity field of the electrically conducting lead-lithium eutectic alloy inside the blanket is highly influenced by the external magnetic field used for plasma confinement, due to a magnetohydrodynamic (MHD) effect. In addition, strong temperature gradients give rise to buoyancy forces, that have a great impact on flow behavior. MHD and convection significantly influences the resulting temperature and velocity fields, and therefore tritium transport. A multi-physics approach of a 3D tritium transport model is presented for a simplified geometry of the WCLL breeding blanket. In particular, MHD, buoyancy forces, advection-diffusion of tritium into the lead-lithium eutectic alloy, transfer of tritium from the liquid interface towards the steel and diffusion of tritium inside the steel have been included in this study. Tritium permeation from $\mathrm{PbLi}$ to the baffle, tritium concentrations and inventories inside the lead-lithium and in the EUROFER baffle have been evaluated.
\end{abstract}

Keywords: DEMO, Liquid metal blanket, WCLL, MHD, Magneto-convection, buoyancy forces, Tritium transport 